\title{
Collapse-to-emergency medical service cardiopulmonary resuscitation interval and outcomes of out-of-hospital cardiopulmonary arrest: a nationwide observational study
}

Soichi Koike ${ }^{1 *}$, Toshio Ogawa ${ }^{2}$, Senzan Tanabe ${ }^{3}$, Shinya Matsumoto ${ }^{1}$, Manabu Akahane ${ }^{2}$, Hideo Yasunaga ${ }^{4}$, Hiromasa Horiguchi ${ }^{4}$ and Tomoaki Imamura ${ }^{2}$

\begin{abstract}
Introduction: The relationship between collapse to emergency medical service (EMS) cardiopulmonary resuscitation (CPR) interval and outcome has been well documented. However, most studies have only analyzed cases of cardiac origin and Vf (ventricular fibrillation)/pulseless VT (ventricular tachycardia). We sought to examine all causes of cardiac arrest and analyze the relationship between collapse-to-EMS CPR interval and outcome in a nationwide sample using an out-of-hospital cardiac arrest (OHCA) registry.

Methods: This was a retrospective observational study based on a nationwide OHCA patient registry in Japan between 2005 and 2008 ( $n=$ 431,968). We included cases where collapse was witnessed by a bystander and where collapse and intervention time were recorded $(n=109,350)$. Data were collected based on the Utstein template. One-month survival and neurologically favorable one-month survival were used as outcome measures. Logarithmic regression and logistic regression were used to examine the relation between outcomes and collapseto-EMS CPR interval.

Results: Among collapse-to-EMS CPR intervals between 3 and 30 minutes, the logarithmic regression equation for the relationship with one-month survival was $y=-0.059 \ln (x)+0.21$, while that for the relationship with neurologically favorable one-month survival was $y=-0.041 \ln (x)+0.13$. After adjusting for potential confounders in the logistic regression analysis for all intervals, longer collapse-to-EMS CPR intervals were associated with lower rates of one-month survival (odds ratio (OR) 0.93, 95\% confidence interval (Cl): 0.93 to 0.93) and neurologically favorable one-month survival (OR $0.89,95 \% \mathrm{Cl} 0.89$ to 0.90 ).
\end{abstract}

Conclusions: Improving the emergency medical system and CPR in cases of OHCA is important for improving the outcomes of OHCA.

\section{Introduction}

The recovery rate in patients suffering cardiopulmonary arrest is generally very low for out-of-hospital cases [1]. In spite of a substantial effort, studies have found that the overall survival in out of hospital cardiac arrest (OHCA) has been stable for almost 30 years [2], or has shown little improvement [3]. As such, establishing an

\footnotetext{
* Correspondence: koikes@adm.h.u-tokyo.ac.jp

'Department of Planning, Information and Management, The University of

Tokyo Hospital, 7-3-1 Hongo, Bunkyo-ku, Tokyo 113-8655, Japan

Full list of author information is available at the end of the article
}

effective emergency medical system (EMS) as well as improving the quality of basic life support (BLS) and advanced cardiac life support (ACLS) are important health policy issues. A number of previous studies have reported that starting cardiopulmonary resuscitation (CPR) earlier results in better outcomes, applying regression models [4], logistic regression models [5,6], and reciprocal models [7] to describe the relationship between collapse-to-EMS CPR interval and outcome.

This study examined the relationship between collapse-to-EMS CPR interval and outcomes based on a

\section{C) Biomed Central}


nationwide OHCA registry. As such, this study is one of the largest studies conducted, in terms of its study population and coverage. There is currently limited documentation on the effects of collapse-to-CPR interval on this scale. Most previous studies have analyzed cardiac origin only, especially initial rhythms of ventricular fibrillation (Vf) or pulseless ventricular tachycardia (VT), A nationwide analysis of all causes of OHCA could provide useful information for establishing more effective EMS systems and the most appropriate allocation of resources.

The aim of this study was to analyze the relationship between the collapse-to-EMS CPR interval, one-month survival, and neurologically favorable outcome using a nationwide OHCA registry between 1 January 2005 and 31 December 2008. This study sought used curve-fitting analysis and potential confounder adjusted odds ratios of the collapse-to-EMS CPR interval. In addition, we sought to discuss the implications of our results for improving EMS systems and the survival of OHCA patients.

\section{Materials and methods Study design}

This study was an observational, retrospective study based on an analysis of a nationwide OHCA registry in Japan from January 2005 to December 2008.

\section{Setting}

Japan is a country with a population of 126 million and universal health insurance coverage. The universal emergency access number enables direct connection to a dispatch center located in the regional fire defense headquarters. Upon receiving a call, the nearest available ambulance is sent to the incident. All expenses for transport are covered by the local government and there is no charge to the patient [7]. The emergency network covers the whole country and almost all OHCA patients undergo emergency transfer to a hospital. Treatment fees for medical services at a hospital are also covered by health insurance. The data used in this study were recorded based on the Utstein template [8]. Items included in the database were the patient's name, sex, age, time of collapse (the time at which sudden falling into unconsciousness was either seen or heard by a witness), the first documented cardiac rhythm, etiology, the CPR or first defibrillation time, the time to return of spontaneous circulation (ROSC), the one-month survival rate, and the one-month CPC (cerebral performance category; as a measure of neurologically favorable survival) $[9,10]$. Location of arrest, survival at discharge, neurological outcome at discharge were not stored in the database. Cardiac etiology was composed of confirmed and presumed cardiac etiology. Although we could not confirm that all times in the database were recorded with standardized timing methods, the proportion of EMS teams practicing daily clock synchronization increased from 39\% in December 2005 to 43\% in July 2007 [11]. These data were transferred from regional fire defense headquarters to the Fire and Disaster Management Agency. Time data were recorded in the system in the unit of minutes.

\section{Selection of participants}

Among the 431,968 OHCA emergency-transferred patients between January 2005 and December 2008, our analysis included cases where collapse was witnessed (that is, collapse was heard or seen by a bystander) but not witnessed by paramedics, the onset time was recorded, and intervention time was less than $120 \mathrm{~min}-$ utes. A total of 109,350 cases were included in the analysis (Figure 1).

One-month survival was not recorded in 2,131 patients (1.9\%) and neurologically favorable survival of 2,356 patients $(2.2 \%)$ was not recorded in the data registry. These cases were excluded from the logistic regression analysis for outcome.

We obtained permission to analyze the data from the Fire and Disaster Management Agency of Japan, and the Agency provided an anonymized dataset. This study was approved by the Institutional Review Board of the Nara Medical University.

\section{Methods of measurement}

Our primary outcome measurement was one-month survival. Neurologically favorable (CPC 1 (Good Cerebral Performance) or 2 (Moderate Cerebral Disability) was used as secondary outcome measurement. Etiology, onemonth survival, and neurologically favorable one-month survival were recorded by EMS personnel in cooperation with attending physicians at medical institutions [12].

\section{Primary data analysis}

After obtaining the patient characteristics and stratified outcome data, the relationship between collapse to EMS CPR interval and outcomes, logarithmic regression analyses were conducted for cases where collapse-to-EMS CPR time was between 3 and 30 minutes.

Logistic regression analyses where the dependent variable was one-month survival or neurologically favorable one-month survival and the independent variables were potential confounders including study year (2005 to 2006/2007 to 2008), sex (male/female), age (seven categories), etiology (cardiac origin/non-cardiac origin), bystander CPR (0/1), public Automated External Defibrillator (AED) (0/1) and collapse-to-EMS CPR interval (minutes) were then performed. In these logistic regression models, collapse-to-EMS CPR interval was treated 


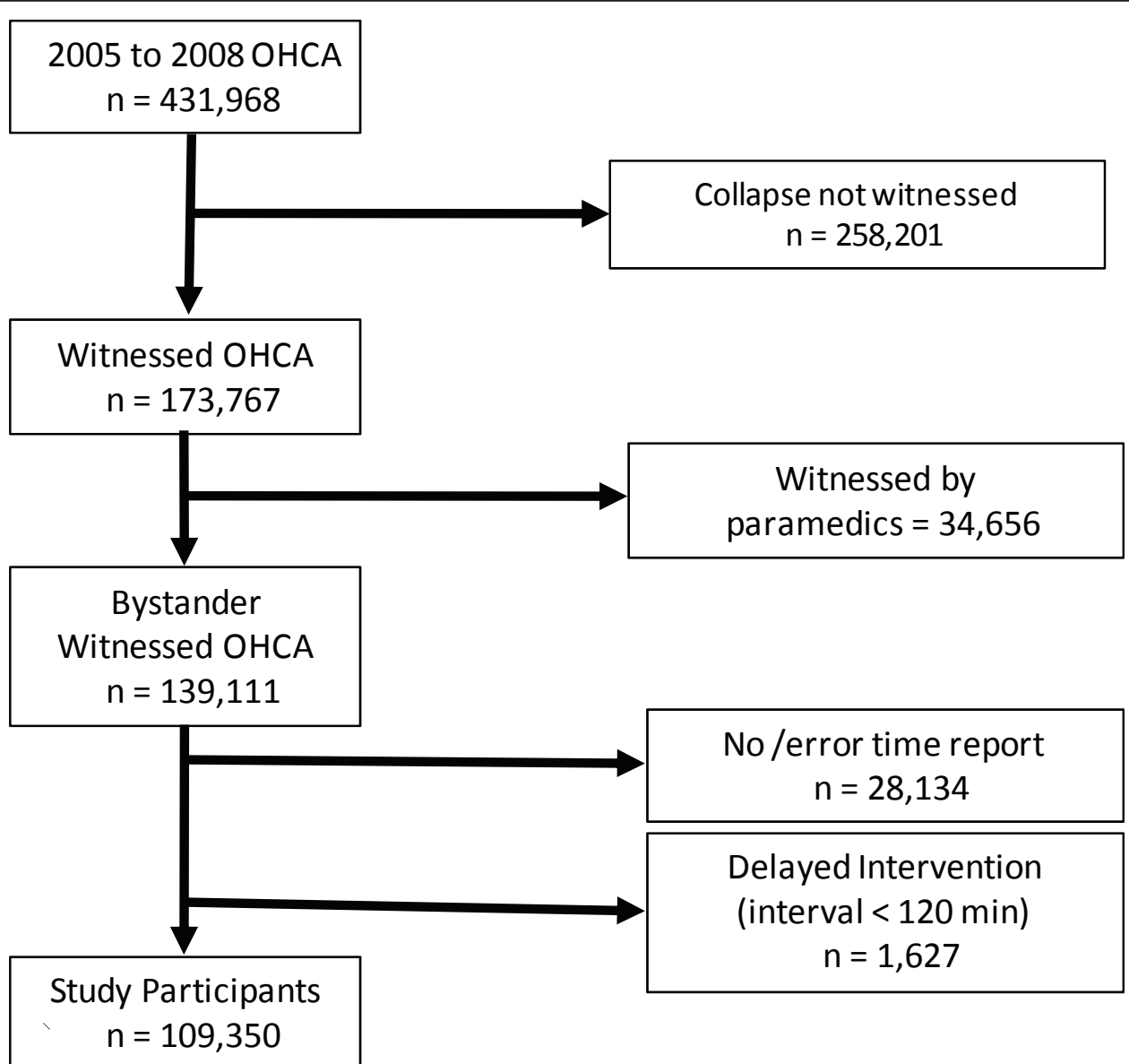

Figure 1 Selection of study participants.

as a continuous variable and included in the model as an independent variable. SPSS 16.0J (SPSS Japan Inc, Tokyo, Japan) was used for statistical analysis.

\section{Results}

\section{Characteristics of study subjects}

The characteristics of study participants are presented in Table 1. Among 109,350 study participants, 67,583 (61.8\%) were male with mean age \pm standard deviation (SD) of $72.9 \pm 18.2$ years old. The presumed etiology in $59,693(54.6 \%)$ cases was cardiac origin, and non-cardiac origin in 49,657 (45.4\%) cases. Bystander CPR was given in $49,122(44.9 \%)$ cases, and $914(0.8 \%)$ were treated by public AED. The mean collapse-to-EMS CPR interval ( \pm $\mathrm{SD})$ was $14.5( \pm 9.3)$ minutes. The mean collapse-to-EMS CPR interval exhibited a positively skewed distribution (Figure 2). The other outcomes stratified by intervention or participant characteristics are presented in Table 2.

\section{Main results}

Among cases where collapse-to-EMS CPR intervals ( $\mathrm{x}$ ) were between 3 and 30 minutes, the logarithmic regression equation for the relationship to one-month survival $(y)$ was $y=-0.059 \ln (x)+0.21\left(R^{2}=0.98\right)$, and that with neurologically favorable one-month survival (y) was $\mathrm{y}=-0.041 \ln (\mathrm{x})+0.13\left(\mathrm{R}^{2}=0.95\right.$; Figure 3$)$.

The results of the logistic regression analyses for onemonth survival and neurologically favorable one-month survival revealed that the 2007 to 2008 period, male, cardiac origin, younger age, bystander CPR, public AED usage were all associated with higher rates of onemonth survival and neurologically favorable one-month survival. After adjusting for the potential confounders presented above, the collapse-to-EMS CPR interval (minutes) was associated with lower survival (odds ratio (OR); 0.93, 95\% CI (confidence interval); 0.93 to 0.93 (0.925 to 0.933$)$ ) and neurologically favorable onemonth survival (OR; 0.89, 95\% CI; 0.89 to 0.90; Table 3).

\section{Discussion}

The present study was an analysis of data from 109,350 patients whose cardiac arrest onset was witnessed. Among cases where the collapse-to-EMS CPR interval was between 3 and 30 minutes, the duration of the 
Table 1 Characteristics of study participants

\begin{tabular}{|c|c|c|}
\hline \multirow{2}{*}{$\begin{array}{l}\text { Variable } \\
\text { Survey year }\end{array}$} & \multicolumn{2}{|c|}{ No.(\%) of patients } \\
\hline & & \\
\hline 2005 & 24,955 & $(22.8)$ \\
\hline 2006 & 26,861 & $(24.6)$ \\
\hline 2007 & 28,126 & $(25.7)$ \\
\hline 2008 & 29,408 & $(26.9)$ \\
\hline Male sex & 67,583 & $(61.8)$ \\
\hline Age, mean (SD), year & 72.9 & $(18.2)$ \\
\hline \multicolumn{3}{|l|}{ Etiology } \\
\hline Presumed cardiac & 59,693 & $(54.6)$ \\
\hline Non-cardiac & 49,657 & $(45.4)$ \\
\hline cerebrovascular disease & 5,331 & (10.7) \\
\hline respiratory diseases & 7,041 & (14.2) \\
\hline cancer & 3,982 & (8.0) \\
\hline exogenous causes & 20,320 & (40.9) \\
\hline other non-cardiac origin & 12,983 & $(26.1)$ \\
\hline non-cardiac origin, subtotal & 49,657 & (100.0) \\
\hline Bystander CPR & 49,122 & (44.9) \\
\hline family & 27,997 & (57.0) \\
\hline friend & 2,202 & $(4.5)$ \\
\hline colleague & 1,610 & (3.3) \\
\hline passerby & 1,767 & (3.6) \\
\hline others & 15,546 & (31.6) \\
\hline type of bystander subtotal & 49,122 & (100.0) \\
\hline Public AED & 914 & $(0.8)$ \\
\hline Intubation & 52,123 & $(47.7)$ \\
\hline Drug & 6,410 & (5.9) \\
\hline \multicolumn{3}{|l|}{ Interval, mean (SD), minutes } \\
\hline collapse-to-call interval & 5.4 & $(8.1)$ \\
\hline collapse-to-arrival & 12.8 & (9.0) \\
\hline collapse-to-EMS contact & 14.0 & $(9.2)$ \\
\hline collapse-to-EMS CPR & 14.5 & $(9.3)$ \\
\hline collapse-to-EMS defibrillation & 16.7 & $(10.1)$ \\
\hline collapse-to-hospital transfer & 36.7 & $(14.5)$ \\
\hline
\end{tabular}

collapse-to-EMS CPR interval was fitted to a logarithmic regression equation to examine its relationship with one-month survival and neurologically favorable onemonth survival. After adjusting for potential confounders in a logistic regression analysis, we found that longer collapse-to-EMS CPR intervals were associated with lower one-month survival and neurologically favorable one-month survival.

Consistent with previous studies, the rate of onemonth survival decreased sharply and gradually leveled off with increasing collapse-to-EMS CPR intervals. The nature of the relationship was the same after adjusting potential confounders including survey year, sex, age, etiology, bystander CPR and public AED. However, in previous studies, $20 \%$ to $34.1 \%$ [13-15] of cases were of non-cardiac origin, whereas the proportion of non-cardiac origin cases in the present study was $45.4 \%$. This difference in etiological proportion should be considered when interpreting the results. The rate of survival following out-of-hospital cardiac arrest of non-cardiac origin has been previously reported to be lower than the survival rate in cases of cardiac arrest of cardiac origin [16]. Most previous studies limited the sample to cardiac origin only, De Mario et al. [17] analyzed all cardiac cases of arrest meeting the Utstein Criteria $(9,273$ patients) between 1991 and 1997, and confirmed that survival exhibited an exponential relationship with time. As our study has a much larger sample, our results provide additional evidence confirming the shape of the survival curve.

The shape of this survival curve suggests two ways to improve the survival of OHCA patients; shortening the collapse-to-CPR interval, or, alternatively, shifting the curve upward by improving the quality of resuscitation attempt.

To quicken response times, potential bystanders could be better educated to activate EMS as soon as possible. In addition, the ambulance system response could be streamlined, strengthening the "chain of survival" [18] concept and reinforcing the importance of an appropriate sequence of pre-hospital care. In Japan, the Fire and Disaster Management Agency reported that the mean response time (call-to-arrival interval) was 7.0 minutes in 2007, increasing from 6.1 minutes in 1997 [19]. In the same period, the number of traffic accidents and accompanying emergency transfers decreased. However, there has been a steady increase in the number of requests for ambulance services. The number of ambulance requests in Japan reached almost 5.3 million per year (almost a 50\% increase in 10 years), but not all calls were genuine emergency cases. It was found that $51.7 \%$ of cases eventually did not require hospitalization. For fully utilizing limited resources in the most appropriate manner, the public should be better educated to call ambulance service only in case of an emergency. In addition, assessment and triage systems should be established at emergency control centers. These changes should be accompanied by improved transportation systems, including methods for determining the hospital to which the transfer should be made as rapidly as possible.

Starting CPR as early as possible would shift the survival curve left. In addition, the survival curve could be shifted upward by improving the quality of resuscitation 


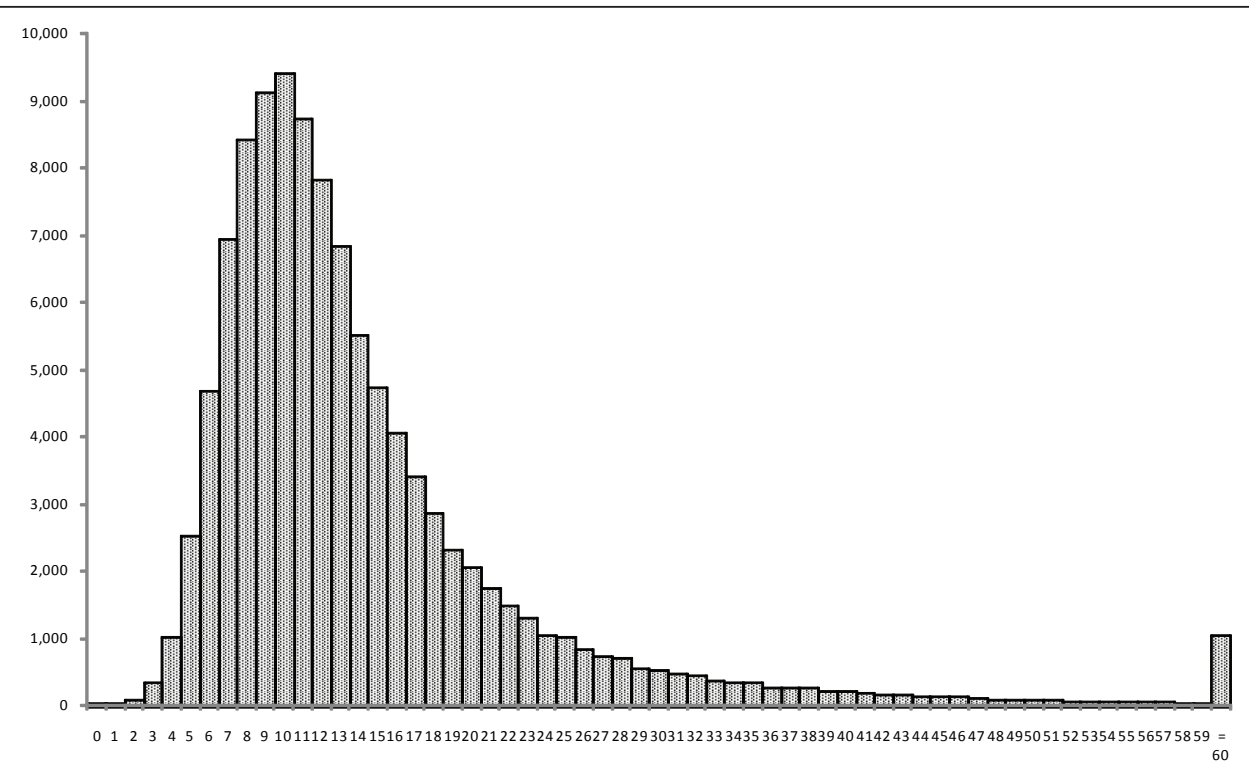

Figure 2 Distribution of collapse-to-EMS CPR intervals (minutes). The distribution of patients by collapse-to-EMS CPR interval (minutes) was presented for 109,350 cases. Cases where the interval was equal or longer than 60 minutes were categorized into one group.

Table 2 One-month survival and neurologically favorable one-month survival

\begin{tabular}{|c|c|c|c|c|}
\hline \multirow[b]{2}{*}{ Survey Year } & \multicolumn{2}{|c|}{$\begin{array}{l}\text { One-month survival } \\
\text { No. (\%) of patients }\end{array}$} & \multicolumn{2}{|c|}{$\begin{array}{l}\text { Neurologically favorable one-month survival } \\
\text { No. (\%) of patients }\end{array}$} \\
\hline & & & & \\
\hline 2005 to 2006 & 3,758 & $(7.3)$ & 1,545 & (3.0) \\
\hline 2007 to 2008 & 5,269 & $(9.2)$ & 2,803 & $(4.9)$ \\
\hline \multicolumn{5}{|l|}{ Sex } \\
\hline Male & 6,087 & $(9.0)$ & 3,134 & $(4.6)$ \\
\hline Female & 2,940 & $(7.0)$ & 1,214 & $(2.9)$ \\
\hline \multicolumn{5}{|l|}{ Age (year) } \\
\hline$<40$ & 940 & $(13.3)$ & 593 & $(8.4)$ \\
\hline 40 to 49 & 569 & $(12.1)$ & 388 & $(8.3)$ \\
\hline 50 to 59 & 1,304 & $(12.7)$ & 779 & $(7.6)$ \\
\hline 60 to 69 & 1,846 & $(11.1)$ & 966 & $(5.8)$ \\
\hline 70 to 79 & 2,116 & (7.6) & 866 & $(3.1)$ \\
\hline 80 to 89 & 1,760 & (5.9) & 606 & $(2.0)$ \\
\hline$\geq 90$ & 492 & (3.8) & 150 & $(1.2)$ \\
\hline \multicolumn{5}{|l|}{ Etiology } \\
\hline Non-cardiac & 3,557 & $(7.2)$ & 1,212 & $(2.4)$ \\
\hline Presumed cardiac & 5,470 & $(9.2)$ & 3,136 & (5.3) \\
\hline \multicolumn{5}{|l|}{ Bystander CPR } \\
\hline no bystander CPR & 3,974 & (6.6) & 1,496 & $(2.5)$ \\
\hline bystander CPR & 5,053 & $(10.3)$ & 2,852 & $(5.8)$ \\
\hline \multicolumn{5}{|l|}{ Public defibrillation } \\
\hline no public AED & 8,414 & $(8.0)$ & 3,927 & $(3.7)$ \\
\hline public AED & 343 & $(37.5)$ & 296 & $(32.4)$ \\
\hline Total & 9,027 & (8.3) & 4,348 & $(4.0)$ \\
\hline
\end{tabular}




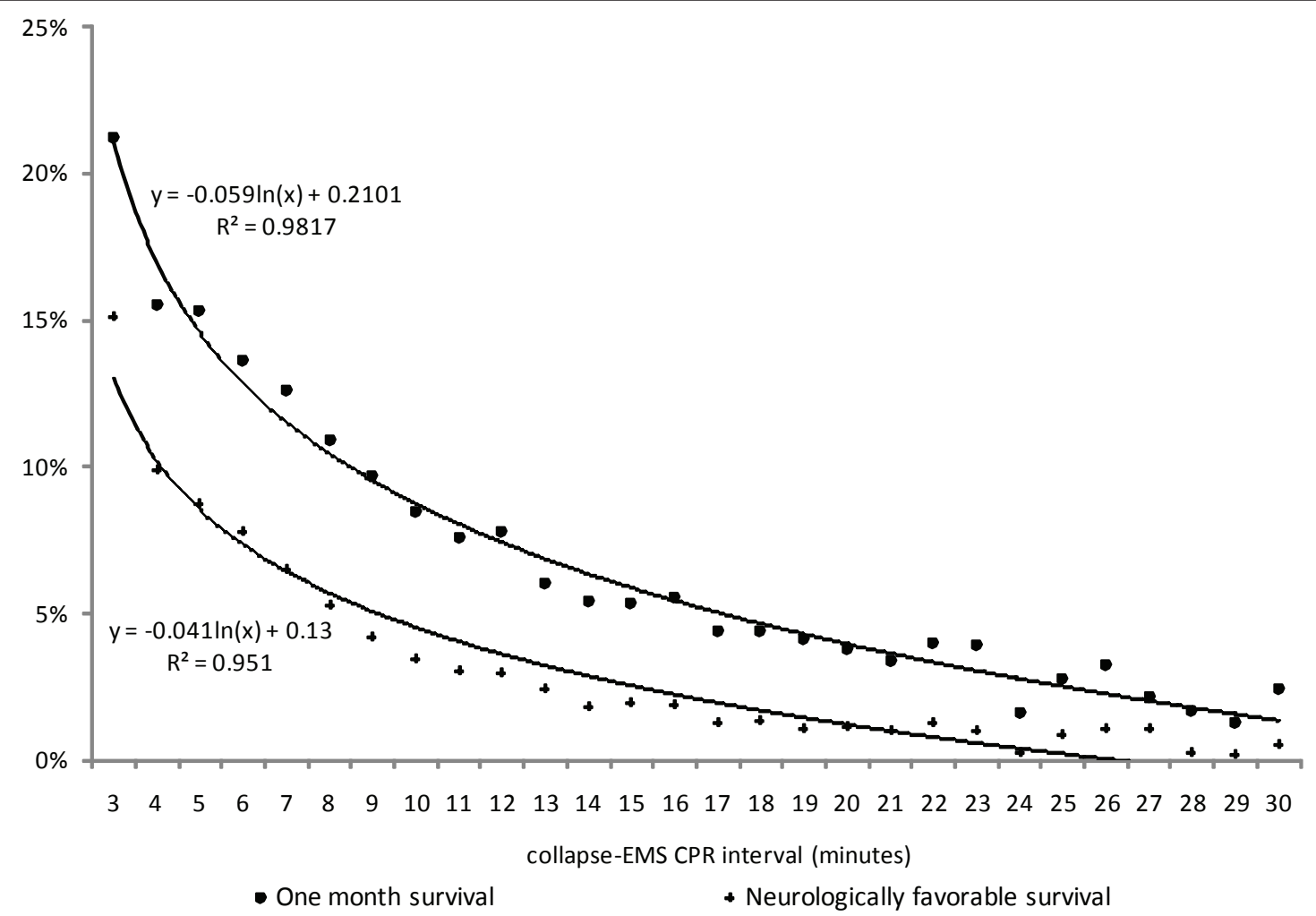

Figure 3 Collapse-EMS CPR interval and outcomes. The relationship between collapse-to-EMS CPR interval and one-month survival (dots) and neurologically favorable one-month survival (crosses) are presented for all cases where collapse-to-EMS CPR interval was between 3 to 30 minutes. Logarithmic regression equations for outcome $(y)$ by collapse-to-EMS CPR interval $(x)$ with $R^{2}$ were calculated and plotted in the graph.

attempts. High-quality CPR is a cornerstone of a system of care that can optimize outcomes [20]. It has been found that improved CPR quality administered by bystanders [21] and ACLS [22] are correlated with survival rates [23]. Various educational courses including mass CPR training and targeted CPR training for family members of patients suffering from cardiovascular diseases are currently available in Japan. Since 1995, new driver's license applicants have been required to take three hours of basic life support (BLS) training at driving schools [24], an attempt to expand BLS knowledge to the general public. Since 2003, Emergency Medical Technicians, (the highest level of ambulance personnel), have been authorized to use AED without online medical control. In the same year, orotracheal intubation was included as a sanctioned method of clearing airways by Emergency Life-Saving Technicians (ELSTs) with 262 hours of additional national standard training. Adrenaline administration by ELSTs with 220 hours of training became legal in 2006 [25]. These combined efforts to improve all four chains of survival could shift the survival curve upward, substantially improving the rate of survival in cases of OHCA.
Several limitations of this study should be considered. First, the time of collapse was based on interviews with laypersons. The witnesses might have been unable to accurately report the time of collapse. Unless there is an exceptional situation (for example, an OHCA event that is videotaped in a casino [26]), obtaining accurate collapse time is problematic, especially based on interviews with laypeople in emergency situations. Isaacs and colleagues [27] reported that layperson estimation of the time and actual measured intervals in cardiac arrest situations were not strongly correlated. As such, the quality of the time interval data represents a serious limitation of the current study. However, this limitation was minimized in the current analysis by excluding values that appeared to be due to error. In addition, the duration of the collapseto-EMS CPR interval exhibited a positively skewed distribution, suggesting that the remaining potential errors in a set of 109,350 cases did not substantially affect the overall conclusions of this study.

A second limitation is that our data were obtained in Japan only. As such, the emergency system and demography might affect the results as unpredicted confounding factors. In our study, more than half of the study 


\begin{tabular}{|c|c|c|}
\hline & One-month survival OR (95\%) & Neurologically favorable one-month survival OR $(95 \%)$ \\
\hline \multicolumn{3}{|l|}{ Survey year } \\
\hline 2005 to 2006 & Reference & Reference \\
\hline 2007 to 2008 & 1.16 (1.11 to 1.22$)$ & $1.41(1.31$ to 1.51$)$ \\
\hline \multicolumn{3}{|l|}{ Sex } \\
\hline Male & Reference & Reference \\
\hline Female & 0.91 (0.87 to 0.96$)$ & 0.83 (0.77 to 0.90$)$ \\
\hline \multicolumn{3}{|l|}{ Age (year) } \\
\hline$<40$ & Reference & Reference \\
\hline 40 to 49 & 0.89 (0.79 to 1.01$)$ & 0.91 (0.78 to 1.07$)$ \\
\hline 50 to 59 & 0.95 (0.86 to 1.05$)$ & 0.82 (0.72 to 0.94$)$ \\
\hline 60 to 69 & 0.83 (0.75 to 0.92$)$ & 0.63 (0.56 to 0.72 ) \\
\hline 70 to 79 & 0.56 (0.52 to 0.62$)$ & 0.34 (0.30 to 0.39$)$ \\
\hline 80 to 89 & 0.41 (0.37 to 0.45$)$ & 0.18 (0.15 to 0.20$)$ \\
\hline$\geq 90$ & 0.24 (0.21 to 0.27$)$ & 0.09 (0.07 to 0.11$)$ \\
\hline \multicolumn{3}{|l|}{ Etiology } \\
\hline Non-cardiac origin & Reference & Reference \\
\hline Cardiac origin & $1.29(1.23$ to 1.35$)$ & 2.61 (2.41 to 2.84 ) \\
\hline \multicolumn{3}{|l|}{ Bystander CPR } \\
\hline No bystander CPR & Reference & Reference \\
\hline Bystander CPR & $1.49(1.40$ to 1.54$)$ & 1.95 (1.81 to 2.09$)$ \\
\hline \multicolumn{3}{|l|}{ Public defibrillation } \\
\hline No public AED & Reference & Reference \\
\hline Public AED & 2.91 (2.44 to 3.47$)$ & 3.52 (2.88 to 4.31$)$ \\
\hline Collapse-EMS CPR interval (minutes) & 0.93 (0.93 to 0.93 ) & 0.89 (0.89 to 0.90$)$ \\
\hline
\end{tabular}

$\mathrm{Cl}$, confidence interval; $\mathrm{OR}$, odds ratio.

participants were 70 years old or older. It is known that the survival rate following CPR in elderly patients is lower than for younger people [28,29]. Although age factors were adjusted for in our logistic regression model, the results of this study may be problematic when applied to other countries with younger population compositions. However, our results will be useful for informing health policy makers in many developed countries with similar emergency systems and demographic profiles.

Third, we did not have data on the hospitals to which patients were transferred, meaning that the data did not reflect the quality of the hospital at which treatment was received. A recent study revealed that treatment at critical care medical centers was associated with better outcomes in cardio pulmonary arrest patients [30]. This may have also acted as a potential confounder.

Despite these limitations, our data provide a valuable investigation of almost all cases of OHCA subjects in Japan over a four-year period, constituting the largestscale study of this issue to date.

\section{Conclusions}

Our analysis of one of the largest samples of OHCA patients, including cases of cardiac and non-cardiac origin, revealed that shorter collapse-to-EMS CPR intervals were associated with better outcomes. Both one-month survival and neurologically favorable onemonth survival curves against collapse-to-EMS CPR interval indicated that improving OHCA outcomes requires interventions to move the curve leftward (by shortening the response time) and upward (by improving the quality of CPR). Improving the emergency medical system, and the speed and quality of CPR in cases of OHCA are the key methods for improving the outcomes of OHCA.

\section{Key messages}

- A nationwide HCA patient registry in Japan confirmed that shorter collapse-to-EMS CPR intervals were associated with better outcomes

- The logarithmic regression equation for the relationship with one-month survival was $y=-0.059 \ln (x)+$ 
0.21 , and that for the relationship with neurologically favorable one-month survival was $\mathrm{y}=-0.041 \ln (\mathrm{x})+0.13$

- The logistic regression analysis after adjusting for potential confounders showed that longer collapse-toEMS CPR intervals were associated with lower rates of one-month survival (OR 0.93, 95\% CI: 0.93 to 0.93 ) and neurologically favorable one-month survival (OR 0.89, 95\% CI 0.89 to 0.90 )

- Improving the emergency medical system, and the speed and quality of CPR in cases of OHCA are key measures for improving the outcomes of OHCA

\section{Abbreviations \\ ACLS: advanced cardiac life support; AED: automated external defibrillator; BLS: basic life support; Cl: confidence interval; CPC: cerebral performance category; CPR: cardiopulmonary resuscitation; ELSTs: emergency life-saving technicians; EMS: emergency medical service; OHCA: out-of-hospital cardiac arrest; ROSC: return of spontaneous circulation; SD: standard deviation; Vf: ventricular fibrillation; VT: entricular tachycardia.}

\section{Acknowledgements}

We thank the National Fire and Disaster Management Agency for providing data.

\section{Author details}

'Department of Planning, Information and Management, The University of Tokyo Hospital, 7-3-1 Hongo, Bunkyo-ku, Tokyo 113-8655, Japan.

${ }^{2}$ Department of Public Health, Health Management and Policy, Nara Medical University School of Medicine, 840 Shijocho, Kashihara, Nara 634-8521, Japan. ${ }^{3}$ Foundation for Ambulance Service Development, Emergency Life-Saving Technique Academy of Tokyo, 4-5 Minami-osawa, Hachioji, Tokyo 192-0364, Japan. ${ }^{4}$ Department of Health Management and Policy, Graduate School of Medicine, The University of Tokyo, 7-3-1 Hongo, Bunkyo-ku, Tokyo 113-8655, Japan.

\section{Authors' contributions}

SK and TI jointly conceived and designed this study. TO conducted data cleaning. SK, TO, ST, MA, HY, HH, SM and TI jointly analyzed and interpreted the data. SK drafted the manuscript. All of the authors jointly reviewed and discussed the manuscript and revised it critically for important intellectual content and approved the draft for submission.

\section{Competing interests}

The authors declare that they have no competing interests.

Received: 10 February 2011 Revised: 22 March 2011

Accepted: 5 May 2011 Published: 5 May 2011

\section{References}

1. Rea TD, Eisenberg MS, Becker $L$, Murray JA, Hearne T: Temporal trends in sudden cardiac arrest: a 25-year emergency medical services perspective. Circulation 2003, 107:2780-2785.

2. Sasson C, Rogers MA, Dahl J, Kellermann AL: Predictors of survival from out-of-hospital cardiac arrest: a systematic review and meta-analysis. Circ Cardiovasc Qual Outcomes 2010, 3:63-81.

3. Nichol G, Thomas E, Callaway CW, Hedges J, Powell JL, Aufderheide TP, Rea T, Lowe R, Brown T, Dreyer J, Davis D, Idris A, Stiell I, Resuscitation Outcomes Consortium Investigators: Regional variation in out-of-hospital cardiac arrest incidence and outcome. JAMA 2008, 300:1423-1431.

4. Larsen MP, Eisenberg MS, Cummins RO, Hallstrom AP: Predicting survival from out-of-hospital cardiac arrest: a graphic model. Ann Emerg Med 1993, 22:1652-1658.

5. Valenzuela TD, Roe DJ, Cretin S, Spaite DW, Larsen MP: Estimating effectiveness of cardiac arrest interventions: a logistic regression survival model. Circulation 1997, 96:3308-3313.
6. Rea TD, Cook AJ, Stiell IG, Powell J, Bigham B, Callaway CW, Chugh S, Aufderheide TP, Morrison L, Terndrup TE, Beaudoin T, Wittwer L, Davis D, Idris A, Nichol G, Resuscitation Outcomes Consortium Investigators: Predicting survival after out-of-hospital cardiac arrest: role of the Utstein data elements. Ann Emerg Med 2010, 55:249-257.

7. Hayashi $Y$, Hiraide A, Morita H, Shinya H, Nishiuchi T, Yukioka H, Ikeuchi H, Matsusaka M, Shigemoto T, Ueshima T, Iwami T, Kai T, Fujii C: Three year longitudinal study for out-of-hospital cardiac arrest in Osaka Prefecture. Resuscitation 2004, 63:161-166.

8. Jacobs I, Nadkarni V, Bahr J, Berg RA, Billi JE, Bossaert L, Cassan P, Coovadia A, D'Este K, Finn J, Halperin H, Handley A, Herlitz J, Hickey R, Idris A, Kloeck W, Larkin GL, Mancini ME, Mason P, Mears G, Monsieurs K, Montgomery W, Morley P, Nichol G, Nolan J, Okada K, Perlman J, Shuster M, Steen PA, Sterz F, et al: Cardiac arrest and cardiopulmonary resuscitation outcome reports: update and simplification of the Utstein templates for resuscitation registries: a statement for healthcare professionals from a task force of the International Liaison Committee on Resuscitation (American Heart Association, European Resuscitation Council, Australian Resuscitation Council, New Zealand Resuscitation Council, Heart and Stroke Foundation of Canada, InterAmerican Heart Foundation, Resuscitation Councils of Southern Africa). Circulation 2004, 110:3385-3397.

9. Brain Resuscitation Clinical Trial I Study Group: A randomized clinical study of cardiopulmonary-cerebral resuscitation: design, methods, and patient characteristics. Am J Emerg Med 1986, 4:72-86.

10. Jennet $B$, Bond $M:$ Assessment of outcome after severe brain damage: a practical scale. Lancet 1975, 305:480-484.

11. [Fire and Disaster Management Agency. Report of the commission on utilization of Utstein Statistics, March 2008]. [http:/www.fdma.go.jp/ neuter/topics/houdou/200417/200417-1houdou_z.pdf].

12. Kitamura T, Iwami T, Kawamura T, Nagao K, Tanaka H, Hiraide A, Implementation Working Group for the All-Japan Utstein Registry of the Fire and Disaster Management Agency: Nationwide public-access defibrillation in Japan. N Engl J Med 2010, 362:994-1004.

13. Hess EP, Campbell RL, White RD: Epidemiology, trends, and outcome of out-of-hospital cardiac arrest of non-cardiac origin. Resuscitation 2007, 72:200-206.

14. Lombardi G, Gallagher J, Gennis P: Outcome of out-of-hospital cardiac arrest in New York City. The Pre-Hospital Arrest Survival Evaluation (PHASE) Study. JAMA 1994, 271:678-683.

15. Kuisma M, Alaspää A: Out-of-hospital cardiac arrests of non-cardiac origin. Epidemiology and outcome. Eur Heart J 1997, 18:1122-1128.

16. Eisenberg MS, Cummins RO, Larsen MP: Numerators, denominators, and survival rates: reporting survival from out-of-hospital cardiac arrest. Am J Emerg Med 1991, 9:544-546.

17. De Maio VJ, Stiell IG, Wells GA, Spaite DW, Ontario Prehospital Advanced Life Support Study Group: Optimal defibrillation response intervals for maximum out-of-hospital cardiac arrest survival rates. Ann Emerg Med 2003, 42:242-250.

18. Cummins RO, Ornato JP, Thies WH, Pepe PE: Improving survival from sudden cardiac arrest: the "Chain of Survival" Concept. Circulation 1991, 83:1832-1847.

19. [Fire and Disaster Management Agency. Current status of emergency medicine and rescue 2008]. [http://www.fdma.go.jp/neuter/topics/houdou/ 2101/210122-2houdou_h.pdf].

20. Hazinski MF, Nolan JP, Billi JE, Böttiger BW, Bossaert L, de Caen AR, Deakin CD, Drajer S, Eigel B, Hickey RW, Jacobs I, Kleinman ME, Kloeck W, Koster RW, Lim SH, Mancini ME, Montgomery WH, Morley PT, Morrison LJ, Nadkarni VM, O'Connor RE, Okada K, Perlman JM, Sayre MR, Shuster M, Soar J, Sunde K, Travers AH, Wyllie J, Zideman D: 2010 American Heart Association Guidelines for Cardiopulmonary Resuscitation and Emergency Cardiovascular Care Science: Part 1: Executive Summary: 2010 American Heart Association Guidelines for Cardiopulmonary Resuscitation and Emergency Cardiovascular Care. Circulation 2010, 122 : S640-S656.

21. Olasveengen TM, Lund-Kordahl I, Steen PA, Sunde K: Out-of hospital advanced life support with or without a physician: effects on quality of CPR and outcome. Resuscitation 2009, 80:1248-1252.

22. Wik L, Kramer-Johansen J, Myklebust H, Sørebø H, Svensson L, Fellows B, Steen PA: Quality of cardiopulmonary resuscitation during out-ofhospital cardiac arrest. JAMA 2005, 293:299-304. 
23. Steen PA, Kramer-Jojansen J: Improving cardiopulmonary resuscitation quality to ensure survival. Curr Opin Crit Care 2008, 14:299-304.

24. Enami M, Takei $Y$, Goto $Y$, Ohta $K$, Inaba H: The effects of the new CPR guideline on attitude toward basic life support in Japan. Resuscitation 2010, 81:562-567.

25. Tanigawa K, Tanaka K: Emergency medical service system in Japan: past, present, and future. Resuscitation 2006, 69:365-370.

26. Valenzuela TD, Roe DJ, Nichol G, Clark LL, Spaite DW, Hardman RG:

Outcomes of rapid defibrillation by security officers after cardiac arrest in casinos. N Engl J Med 2000, 343:1206-1209.

27. Isaacs E, Callaham ML: Ability of laypersons to estimate short time intervals in cardiac arrest. Ann Emerg Med 2000, 35:147-154

28. Engdahl J, Bång A, Lindqvist J, Herlitz J: Can we define patients with no and those with some chance of survival when found in asystole out of hospital? Am J Cardiol 2000, 86:610-614.

29. Iwami T, Hiraide A, Nakanishi N, Hayashi Y, Nishiuchi T, Yukioka H, Yoshiya I, Sugimoto H: Age and sex analyses of out-of-hospital cardiac arrest in Osaka, Japan. Resuscitation 2003, 57:145-152.

30. Kajino K, Iwami T, Daya M, Nishiuchi T, Hayashi $Y$, Kitamura T, Irisawa T, Sakai T, Kuwagata Y, Hiraide A, Kishi M, Yamayoshi S: Impact of transport to critical care medical centers on outcomes after out-of-hospital cardiac arrest. Resuscitation 2010, 81:549-554.

doi:10.1186/cc10219

Cite this article as: Koike et al:: Collapse-to-emergency medical service cardiopulmonary resuscitation interval and outcomes of out-of-hospital cardiopulmonary arrest: a nationwide observational study. Critical Care 2011 15:R120.

\section{Submit your next manuscript to BioMed Central} and take full advantage of:

- Convenient online submission

- Thorough peer review

- No space constraints or color figure charges

- Immediate publication on acceptance

- Inclusion in PubMed, CAS, Scopus and Google Scholar

- Research which is freely available for redistribution

Submit your manuscript at www.biomedcentral.com/submit 